\title{
Acoustically-equipped Ocean Gliders for Environmental and Oceanographic Research
}

\author{
David K. Mellinger \\ Oregon State University \\ Hatfield Marine Science Center \\ 2030 SE Marine Science Drive \\ Newport, OR 97365, USA \\ phone: (541) 867-0371 fax:(541) 867-3907 email: David.Mellinger@oregonstate.edu \\ Award Number: N00014-13-1-0682 \\ http://www.bioacoustics.us
}

\section{LONG-TERM GOALS}

The long-term goal of this project is to establish acoustically-equipped gliders for use in research on marine mammal occurrence and behavior. The instruments purchased with this grant will significantly enhance our DoD-funded work, including both currently-funded research and proposed research.

\section{OBJECTIVES}

The Navy observes and studies marine mammals, both to better understand marine mammal occurrence and behavior and also to mitigate the deleterious effects of its operations on marine mammals. To facilitate acquisition of marine mammal data, we will purchase two gliders for passiveacoustic marine mammal observation and research. Since 2008 we have been collaborating with the Applied Physics Laboratory at the University of Washington (APL-UW) to develop, test, and use Seagliders ${ }^{\mathrm{TM}}$ (owned by UW) equipped with passive acoustic sensors and recording system. This system has been successfully deployed many times now, and we propose to purchase two of these acoustically-equipped gliders for enhancing our DoD-funded research. Enhancement will come in the several areas: (1) marine mammal acoustic research and monitoring from gliders, for which these new gliders will allow us to operate glider missions more often and accelerate the research cycle; (2) marine mammal density estimation research, for which these new gliders will allow us to gather more data, test and calibrate methods, and better develop glider-specific density estimation methods; (3) detection, classification, and localization (DCL) research, for which these new gliders will allow collection of much more data, create a faster cycle time for developing DCL algorithms, and develop better gliderspecific DCL methods; (4) acoustic propagation research, for which these new gliders will allow us to collect environmental data key to measuring sound speed (temperature, salinity) simultaneously with collection of acoustic data to measure propagation, and collect such data repeatedly over an extensive geographic area; (5) ocean noise research; (6) ecosystem process research, for which these new gliders will allow us to observe high-trophic-level marine mammals in conjunction with other parameters, and enable collaboration with researchers studying other physical and biological processes; and (7) research and monitoring on Navy ranges. 


\section{Report Documentation Page}

Form Approved

OMB No. 0704-0188

Public reporting burden for the collection of information is estimated to average 1 hour per response, including the time for reviewing instructions, searching existing data sources, gathering and maintaining the data needed, and completing and reviewing the collection of information. Send comments regarding this burden estimate or any other aspect of this collection of information,

including suggestions for reducing this burden, to Washington Headquarters Services, Directorate for Information Operations and Reports, 1215 Jefferson Davis Highway, Suite 1204, Arlington

VA 22202-4302. Respondents should be aware that notwithstanding any other provision of law, no person shall be subject to a penalty for failing to comply with a collection of information if it

does not display a currently valid OMB control number.

1. REPORT DATE

30 SEP 2014

4. TITLE AND SUBTITLE

Acoustically-equipped Ocean Gliders for Environmental and

Oceanographic Research

6. AUTHOR(S)

7. PERFORMING ORGANIZATION NAME(S) AND ADDRESS(ES)

Oregon State University,Hatfield Marine Science Center,2030 SE Marine Science Drive,Newport,OR,97365

9. SPONSORING/MONITORING AGENCY NAME(S) AND ADDRESS(ES)

3. DATES COVERED

00-00-2014 to 00-00-2014

5a. CONTRACT NUMBER

5b. GRANT NUMBER

5c. PROGRAM ELEMENT NUMBER

5d. PROJECT NUMBER

5e. TASK NUMBER

5f. WORK UNIT NUMBER

8. PERFORMING ORGANIZATION

REPORT NUMBER

10. SPONSOR/MONITOR'S ACRONYM(S)

11. SPONSOR/MONITOR'S REPORT

NUMBER(S)

12. DISTRIBUTION/AVAILABILITY STATEMENT

Approved for public release; distribution unlimited

13. SUPPLEMENTARY NOTES

14. ABSTRACT

15. SUBJECT TERMS

16. SECURITY CLASSIFICATION OF:

a. REPORT

unclassified b. ABSTRACT

unclassified c. THIS PAGE

unclassified
17. LIMITATION OF ABSTRACT

Same as

Report (SAR)
18. NUMBER 19a. NAME OF

OF PAGES RESPONSIBLE PERSON

5

Standard Form 298 (Rev. 8-98) Prescribed by ANSI Std Z39-18 


\section{APPROACH}

Ocean gliders equipped with passive acoustic systems provide a low-cost means to study marine mammals and related oceanic processes. They can be used for long-duration, large-area surveys to determine when and where different species are present. They can simultaneously sample physical properties such as temperature, salinity, dissolved oxygen, and nutrients, as well as estimating currents by comparing glider movements expected from direction and speed measurements and the actual movements as measured by GPS positions. These observations enable greater understanding of the factors driving marine mammal occurrence and populations.

Acoustically-equipped gliders can also be used to mitigate possible harm to the mammals. They could also form a component of a near-real-time detection and reporting system to warn naval operators, including sonar operators and leaders of exercises employing explosives, of the presence of cetacean species of interest so they could take appropriate steps to mitigate potential harm. This is possible because gliders, unlike autonomous hydrophones moored on the seafloor, are capable of near-real-time response to signals detected from marine mammals. This requires, of course, a glider-resident detection/classification system that is capable of knowing when any species of interest are present. We have been working for years on such a system, and have successfully deployed it to detect beaked whale species of interest from a glider.

Acoustically-equipped gliders for marine mammal research (Fig. 1) could also be used to evaluate any potential impacts of Navy activities (sonar, use of explosives, multiple-ship presence, etc.), or other human activities in the ocean such as shipping, on marine mammals exposed to these activities. Because gliders can persist for months at a time, they are well-suited for experiments that measure marine mammal occurrence and acoustic behavior before, during, and after exposure.

We have been collaborating since 2008 with Neil Bogue and Jim Luby of the Applied Physics Laboratory, University of Washington (APL-UW) to develop and use acoustically-equipped gliders for marine mammal research. We have developed a system for sensing and recording ocean sound and detecting marine mammal vocalizations in it. Via the glider's satellite communications system, the glider can report such detections in near-real time - within minutes to a few hours - after the animal produces them. Also using this satellite communications system, we can also respond immediately to detections by changing the glider's mission if desired. For example, if during a wide-area survey an unusual species of beaked whale is found, the glider can be reprogrammed to remain on station and determine how long that species remains present, as well as recording its acoustic behavior and hence its foraging behavior.

During this collaboration, we have had successful deployments of two acoustically-equipped gliders to detect and study cetaceans in the Puget Sound area, at the Navy's AUTEC range in the Bahamas, off the Kona coast of Hawai'i (Klinck et al., 2012), and off the coast of Washington and Oregon. These two gliders are owned and operated by APL-UW. 


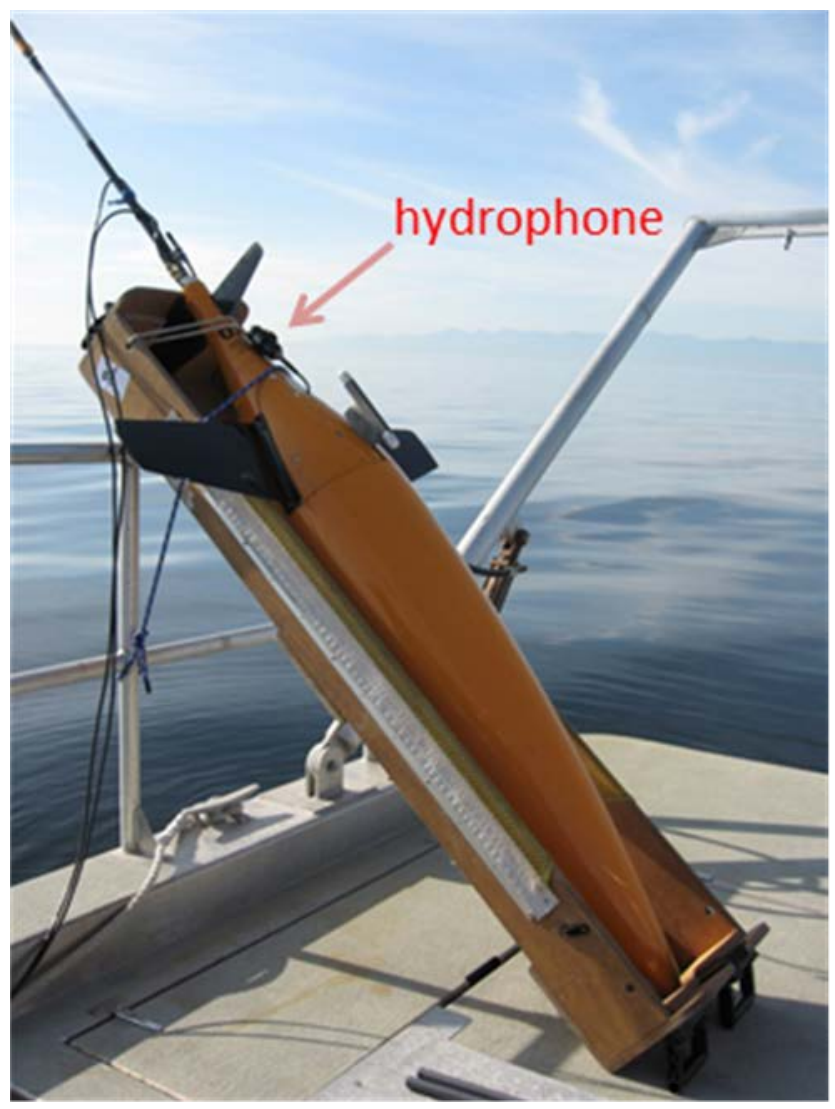

Fig. 1. A Seaglider ${ }^{\mathrm{TM}}$ equipped for passive acoustics.

\section{WORK COMPLETED}

Two Seagliders have been purchased from Kongsberg, Inc. (Lynnwood, WA) and were delivered to OSU in early September 2014. We are currently working on establishing a reliable communication link between the two Seagliders and OSU's Iridium base station. This effort will be completed in the next few weeks. APL-UW has completed the revisions of the passive acoustic monitoring (PAM) boards that are to go on the gliders. The modified PAM board now features 8 microSD memory card slots providing a total of approximately $512 \mathrm{~GB}$ of data storage ( 1 TB with FLAC audio compression enabled). The board is currently being used in an acoustic survey in the South Pacific. After completion of this survey and potential additional minor PAM board modifications, APL-UW will install the new PAM boards on the OSU Seagliders.

\section{RESULTS}

Two Seagliders have been purchased from Kongsberg, Inc. (Lynnwood, WA) and shipped to our laboratory. We are currently working on [a] establishing a reliable communication link and [b] integrating the PAM board. 


\section{IMPACT/APPLICATIONS}

The U.S. Navy's operations, including use of tactical sonars, have been linked to marine mammal strandings and fatalities (Barlow and Gisiner, 2006), particularly of beaked whales, which appear to be particularly sensitive to mid-frequency sonars. These events have generated legal challenges to the Navy's peacetime use of mid-frequency sonar, and have limited the Navy's at sea anti-submarine warfare training time. A mobile, persistent system that can detect, classify, and localize marine mammal species of interest can help resolve the conflict between the Navy's need for realistic training of sonar operators and the Navy's desire to protect the marine environment, especially marine mammal populations, worldwide.

Furthermore, a system capable of simultaneously monitoring other aspects of the marine environment will allow better understanding of marine mammal occurrence, populations, and movements. As for any organism, occurrence of marine mammals is closely linked to the availability of food resources (e.g., Baumgartner et al., 2003) and the presence of predators, and food resources are linked to physical and biological ocean processes (e.g., Tynan et al., 2005). By simultaneously observing multiple levels of these processes, an integrated view of the factors driving marine mammal occurrence may be achieved (e.g., Croll et al., 2005).

\section{RELATED PROJECTS}

We have been collaborating with Neil Bogue and Jim Luby of the Applied Physics Laboratory, University of Washington (APL-UW) for development and use of gliders for research on marine mammals (N000141010387). APL-UW owns the three acoustically-equipped Seagliders that have been used in this collaboration. Our purchase of two additional gliders will strengthen this line of research in several ways:

- We will be able to deploy the gliders more often for marine mammal monitoring. In the past we have sometimes been limited by the availability of APL-UW personnel to do projects; marine mammal monitoring is only a small component of their work, and finding times when they are available can be difficult.

- When we collaborate with APL-UW, we would have a total of five gliders, allowing us to cover larger areas, or cover the same areas at greater glider density. This will enhance our ability to research marine mammals through acoustics.

- When we collaborate, we could extend our mission time to have two gliders operating essentially indefinitely. We would do this by deploying two refurbished gliders each time we recover two other gliders at the end of their deployment. This will allow us to investigate the use of gliders for acoustic study of marine mammals over much longer time scales and, potentially, larger areas than we can at present. Without collaborating, we can keep only one glider deployed indefinitely in the same manner.

\section{REFERENCES}

Barlow, J., and R. Gisiner. 2006. Mitigating, monitoring, and assessing the effects of anthropogenic sound on beaked whales. J. Cetacean Res. Manage. 7(3):239-249. 
Baumgartner, M.F., T.V.N. Cole, R.G. Campbell, G.J. Teegarden, and E.G. Durbin. 2003. Associations between North Atlantic right whales and their prey, Calanus finmarchicus, over diel and tidal time scales. Mar. Ecol. Prog. Ser. 264:155-166.

Croll, D.A., B. Marinovic, S. Benson, F.P. Chavez, N. Black, R. Ternullo, and B.R. Tershy. 2005. From wind to whales: trophic links in a coastal upwelling system. Mar. Ecol. Prog. Ser. 289:117130.

Klinck, H., D.K. Mellinger, K. Klinck, N.M. Bogue, J.C. Luby, W.A. Jump, G.B. Shilling, T. Litchendorf, A.S. Wood, G.S. Schorr, and R.W. Baird. 2012. Near-real-time acoustic monitoring of beaked whales and other cetaceans using a Seaglider. PLoS ONE 7(5):e36128, doi:10.1371/journal.pone.0036128.

Tynan, C.T., D.G. Ainley, J.A. Barth, T.J. Cowles, S.D. Pierce, and L.B. Spear. 2005. Cetacean distributions relative to ocean processes in the northern California Current System. Deep Sea Res. II 52:145-167. 